\title{
GIS Integration Model of Metropolitan Area Sustainability Index (MASI). The Case of Paris Metropolitan Area
}

\author{
Mărgărit-Mircea NISTOR ${ }^{*_{1}, 2}$, Alexandru Sabin NICULA ${ }^{*_{2}, 3}$, Ionel HAIDU4, Ioan SURDU², \\ Iulius-Andrei CAREBIA5, Dănuţ PETREA 6 \\ * Corresponding author \\ ${ }^{* *}$ Equal contribution with the corresponding author \\ ${ }^{1}$ Earth Research Company, Department of Geoengineering, Cluj-Napoca, ROMANIA \\ ${ }^{2}$ Romanian Academy, Centre of Mountain Economy of the National Institute for Economic Research "Costin C. Kiriţescu”, Bucharest, \\ ROMANIA \\ 3 Babeş-Bolyai University, Faculty of Geography, Centre for Research on Settlements and Urbanism, Cluj-Napoca, ROMANIA \\ 4 University of Lorraine, LOTERR Laboratory, Metz, FRANCE \\ ${ }_{5}^{5}$ German European School, SINGAPORE \\ ${ }^{6}$ Babeş-Bolyai University, Faculty of Geography, Department of Physical and Technical Geography, Cluj-Napoca, ROMANIA \\ E-mail: renddel@yahoo.com
}

DOI: 10.24193/JSSP.2019.1.04

https://doi.org/10.24193/JSSP.2019.1.04

K e y w o r d s: land cover, Metropolitan Area Sustainability Index (MASI), urban sustainability index, Paris Metropolitan Area, GIS, development indicators

\begin{abstract}
A B S T RA C T
Territorial sustainability is often related to the land cover and local resources. Land cover data are used more than other remote sensing and digital photography methods for determining and analysing the information collected from a certain region. However, having the dynamic evolution of urban areas in developed countries, such methods and indicators should be considered in order to assess their development directions and sustainability. Between 1990 and 2012, Paris Metropolitan Area (PMA) recorded increases in urban land due to the continuous expansion of the built-up area. In this study, we proposed to calculate the Metropolitan Area Sustainability Index (MASI) by using a GIS procedure, incorporating the land cover of PMA for two reference years (1990 and 2012). Six indicators were selected for the PMA territory based on which the City Index was calculated. Two correction factors, namely the Environmental Capacity of Development and the Land Restriction for Development, were defined in order to develop the MASI of PMA. High MASI values were found in the north-central, southern, and western parts of the PMA, while lower values were identified in the peripheral areas. This study suggests that the proposed method is reliable for the territorial sustainability assessment. The methodology and original maps represent useful tools for future urban planning in large cities.
\end{abstract}

\section{INTRODUCTION}

Nowadays, policy-makers and urban planners are taking into account the concept of sustainable development (Singh et al., 2012). This concept was first proposed during the 1972 United Nations Conference in Stockholm (Lu and Ke, 2018) and was since studied extensively in various scientific domains. One dimension of sustainable development, as derived from the Brundtland Report, is its focus on safeguarding long-term ecological sustainability, support the human requirements in terms of resources and space development (Holden et al., 2014). At the same time, the majority of states are promoting the intragenerational and intergenerational equity statuses (Holden et al., 2014). In most of the cases, sustainable 
development policies follow the principles stated at the Rio de Janeiro Conference in 1992 (Boliset al., 2014).

Metropolitan areas should have proper practices and tools to assess the sustainability of their territories. Moreover, the determination of territorial sustainability represents an indispensable instrument for all large urban areas. Cities represent some of the most important global entities and their functionality may support the future sustainability (Mori et al., 2015). Moreover, the 'world's urban population reached 4 billion in 2015 and is prone to reach 6.3 billion by 2050. In the last 70 years, the percentage of urban population increased from $30 \%$ in 1950 to $54 \%$ in 2015 and is expected to reach almost 70\% in 2050, and $100 \%$ in 2092 (Batty, 2011; Huang et al., 2015). In 1800, solely $2 \%$ of the world's population lived in urban areas (Angel et al., 2016; Kanyinda et al., 2017). As urban expansion will certainly reach alarming rates and the pressure of metropolitan areas will continue to intensify, the sustainable management of future urban development becomes a priority for everybody. Strong transformation processes are characteristic to metropolitan areas and quantitative research methods regarding innovation (Păcurar et al., 2016) and sustainability indices are needed in order to explore territorial issues (Nicula et al., 2017). In addition, the decision-making process is generally correlated with coherent indicators and sustainability objectives set by metropolitan areas (Carli et al., 2018).

It is difficult to find sustainability indices that could precisely predict or assess the situation in a territory. Thus, the methodology we propose in order to spatially evaluate the main sustainability indicators (social, economic, environmental etc.) is through the use of GIS technology. The Paris Metropolitan Area (PMA) was chosen for this analysis because (i) it is a highly urbanized area and (ii) the urban area has extended considerably in the last half-century. Recent studies indicated that the area of Paris is facing the current climate change challenges, which implies confining $\mathrm{CO}_{2}$ emissions. Due to this, new features and characteristics will be designated for the future built-up areas (Masson et al., 2012). In addition, Csurgó et al. (2016), in a comparative study, tried to identify the innovation and sustainability capacity of rural areas on the outskirts of Paris and Budapest. In their study, the rural areas of Paris and Budapest metropolitan areas were analysed, along with the governance methods, food and cultural components of rural-urban relations. The difference consists in the multi-level governance methods for Paris and the isolated form of rural governance correlated with the rural-urban local food link in Budapest metropolitan area.

Kılkış $(2015,2016)$ analysed the sustainability concept of the cities in the South-East of Europe. In his studies, the analysis of 12 cities was completed using a composite indicator with 7 dimensions. More recently, 40
Chaloupková et al. (2018) have proposed the spatial creativity growth index in the Czech Republic using the sub-indicators of talent, technology and tolerance. Research on the sustainability of metro areas can be classified into two major categories. The first category comprises studies focused on developing environmental sustainability indices (Sands and Podmore, 2000; Sutton, 2003; Lee and Huang, 2007; Siche et al., 2008; Gardi et al., 2010; Mori and Christodoulou, 2012; Mori and Yamashita, 2015; Mori et al., 2015; Turón and Gomis, 2016; Correa Ayram et al., 2017). The second category includes studies focused on testing and assessing the above-mentioned indices and sustainability in general within different metropolitan areas such as Kansas City Metropolitan Area (Johnson and Swearingen, 2010), Greater Cincinnati Metropolitan Area (Gonzalez-Mejía et al., 2012), Hangzhou Metropolitan Area (Wu et al., 2013), Metropolitan Area of Concepción (Rojas et al., 2013). Bircol et al. (2018) have analysed land use by employing GIS technology to determine the need for protection in the Ribeirão Preto area of Brazil. Di Lucia et al. (2018) have assessed the sustainability outcomes based on landscape designing. In Poland, MilczarekAndrzejewska et al. (2018) have expressed their concern regarding the land use policy of the agricultural areas and the major conflicts at the regional level.

The major objectives of this study are (i) to identify the suitable indicators for the sustainability index in a large city, (ii) to propose a method to assess the sustainability at spatial scale based on land cover and by integrating these indicators, and (iii) to apply this methodology for Paris Metropolitan Area for the reference years 1990 and 2020.

\section{STUDY AREA}

The PMA spreads from $1^{\circ} 26^{\prime} 47^{\prime \prime}$ to $3^{\circ} 33^{\prime} 30^{\prime \prime}$ longitude East and from $48^{\circ} 7^{\prime} 12^{\prime \prime}$ to $49^{\circ} 14^{\prime} 31^{\prime \prime}$ latitude North (Fig. 1).

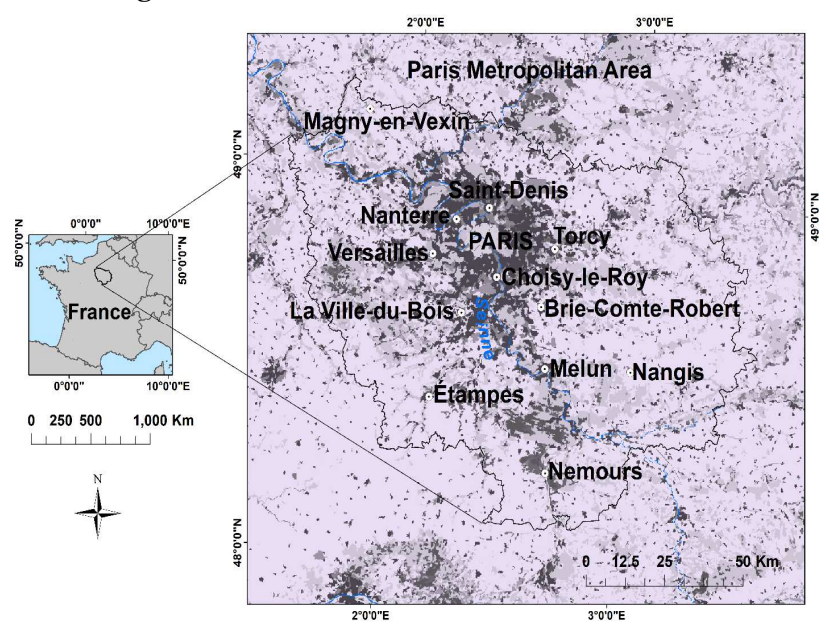

Fig. 1. Location of the PMA on the France map and the main localities. 
Geographically, the study area is located in the north of France and includes the city of Paris and about 1700 communes. This area is characterized by lowlands with altitudes less than $300 \mathrm{~m}$ above the sea level. The metropolitan area has steadily expanded. With a population of 12.5 million in 2015, compared to 10.3 million in 1990, the PMA covers $17,174 \mathrm{~km}^{2}$, of which only $16 \%$ is urban (Cox, 2018).

Urban and constructed areas are mainly concentrated in the northern and north-central side of the PMA, with many localities around (e.g. Magny-en-
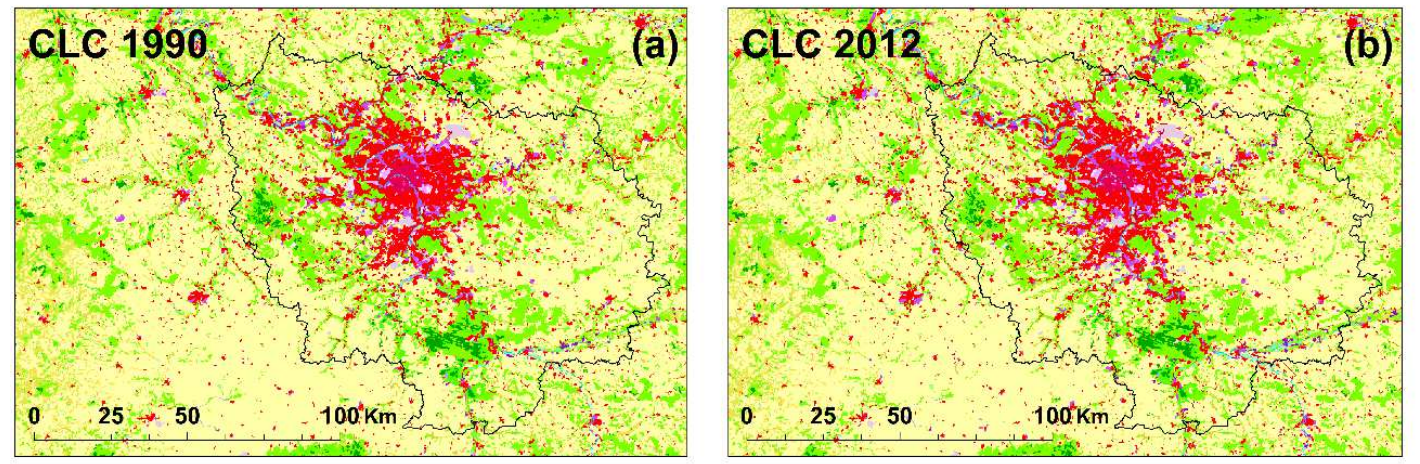

CLC 1990 and 2012

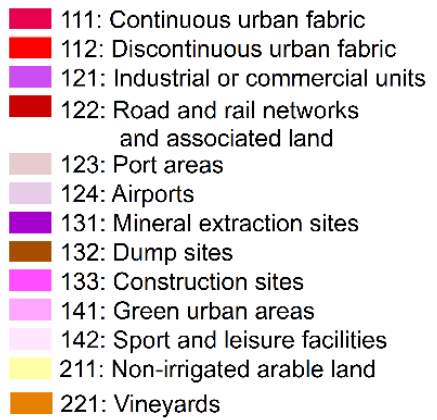

Vexin, Saint-Denis, Nanterre in the north, Versailles, La Ville-du-Boisin in western and west-central sides, Étampes, Melun, Nemours in South, Nangis in East, Torcy, Choisy-le-Roy and Brie-Comte-Robert). In the eastern side and in peripheral areas, agricultural areas, including fruit plantations, tend to predominate. Forests extend in the southern and western sides (Figures 2a and b). The importance of the land cover composition is reflected in the sustainability indicators and final calculation of sustainability index at spatial scale. (CLC 2012).

Fig. 2. Land cover of the PMA: (a) Land cover pattern related to past (CLC 1990). (b) Land cover pattern related to present

\section{MATERIALS AND METHODS}

\subsection{Land cover data}

For the representation of sustainable indicators at the spatial scale of Paris Metropolitan Area, the CORINE Land Cover 1990 and 2012 databases were used. For the data extraction of land cover pattern for 1990 and 2012, raster data at $250 \mathrm{~m}^{2}$ resolution were used (Figures 2a and 2b). These two databases are available at Copernicus Land Monitoring Services (2012) (http://land.copernicus.eu/).

Based on the land cover data and specialized studies, six indicators reflecting the city sustainability were incorporated into the 'City Index' (Eq. (1)). At the same time, the correction factors of 'Environmental Capacity of Development' and 'Land Restriction for Development' were defined. The land cover maps have high-resolution of $250 \mathrm{~m}^{2}$ (1990 and 2012) and medium resolution of $1000 \mathrm{~m}^{2}$ (2040). Since the indicators and
City Index were calculated considering a $5 \mathrm{~km}^{2}$ network, the resolution of the land cover does not directly affect the performance of the calculations.

\subsection{Indicators and the City Index}

The following indicators were chosen and defined in order to set up the 'City Index': 'Economic', 'Industrialization', 'Social', 'Agricultural', 'Environmental', and 'Naturality'. These indicators support the capacity of development in the complex urban areas and their surroundings (Kılkış, 2015). The sustainability of PMA was determined through MASI, which contains the 'City Index', and two correction factors, namely 'Environmental Capacity of Development' and 'Land Restriction'.

The 'City Index' is based on the most sensitive indicators that could be found in urban areas. These indicators were calculated as the ratio between the area of each one and a $5 \mathrm{~km}^{2}$ unit, which was chosen to be 
used in this survey. The units are representing the square network generated by 'Create Fishnet' function and processed together with the vector features of PMA (e.g. boundary, land cover data). This procedure of the network grid with equal units follows the approach of Gardi et al. (2010), which is based on the administrative units of Emilia-Romagna region and agricultural data to evaluate the Land Use Sustainability Index of the region using the land cover data. In this paper, the approach was slightly modified, by including the two layers of correction factors, instead of biodiversity. This detail is more important for the large cities scale due to their dynamic expansion.

\subsection{Correction factors}

In the urban areas, there are specific parcels with certain functionality that cannot be easily changed or used for another type of activities. Such kind of land could refer to transport infrastructure, defence areas, lakes etc. On the other hand, some of these factors may support development much easier (for instance, the development of non-utilized lands. For this reason, correction factors were proposed in this study and were integrated into the sustainability index. These factors may slightly differ from city to city. Normally, the correction factors represent the areas that can change (e.g. Environmental Capacity for Development) or not change (e.g. Land Restriction for Development) their designation.

In this study, the correction factors were applied due to the possibility of many decisions to be made at the administrative level, which may change the designation of various types of areas (e.g. agricultural land into industrial, bare land into residential, etc.). The 'Environmental Capacity of Development' is a strong factor which indicates the land cover types that may sustain the new built-up areas and allow for infrastructure constructions. In opposition, the 'Land Restriction for Development' is a weak factor, because it represents the territories that are mainly composed of areas with very low capacity for development and society welfare. The correction factors of 'Environmental Capacity of Development' and 'Land
Restriction for Development' have normalized values that range from 0.5 (minimum value) to 1 (maximum value). Gardi et al. (2010) proposed this type of normalization to avoid the division at $\mathrm{o}$, but also because of the standard methodology they followed. The meaning of the correction factors values indicates that the minimum and maximum values are decisive for the types of land cover that present a strong or weak capacity for development. In the base of these two extremes, the remained land cover types were classified accordingly, between 0.5 and 1 (Table 1).

Table 1. Correction factors values applied for sustainability in PMA.

\begin{tabular}{l|cc}
\multicolumn{1}{c|}{ Land type } & ECD** & LRD \\
\hline Continuous urban fabric & 0.50 & 0.75 \\
Discontinuous urban fabric & 0.50 & 0.75 \\
Industrial or commercial units & 0.50 & 0.75 \\
Sport and leisure facilities & 0.80 & 0.75 \\
Airports & 0.50 & 1.00 \\
Mineral extraction sites & 0.90 & 0.60 \\
Non-irrigated arable land & 0.70 & 0.80 \\
Fruit trees and berry plantations & 0.70 & 0.80 \\
Land principally occupied by agriculture, & 0.70 & 0.80 \\
with significant areas of natural vegetation & 0.70 & 0.80 \\
Complex cultivation patterns & 0.60 & 0.90 \\
Transitional woodland-shrub & 0.80 & 0.75 \\
Pastures & 0.60 & 0.90 \\
Coniferous forest & 0.60 & 0.90 \\
Broad-leaved forest & 0.50 & 1.00 \\
Inland marshes & 0.50 & 1.00 \\
Water bodies & 0.50 & 1.00 \\
Water courses & & \\
*ECD - Environmental Capacity for Development. & & \\
*** LRD - Land Restriction for Development. & &
\end{tabular}

The 0.5 value is the most improbable for the index. Figure 3 shows the general framework of the methodology. The mathematical operations, both in the attribute tables and raster data were completed in ArcGIS. This software has worldwide applicability due to its powerful tools for territorial analyses (Mokoena and Musakwa, 2018; Nistor, 2018).

$$
C I=\left(S_{i} \times 20\right)+\left(I_{i} \times 20\right)+\left(E c_{i} \times 20\right)+\left(A_{i} \times 10\right)+\left(E n_{i} \times 20\right)+\left(N_{i} \times 20\right)
$$

where:

$$
\begin{aligned}
& S_{i} \text { - social indicator; } \\
& I_{i} \text { - industrialization indicator; } \\
& E c_{i} \text { - economic indicator; } \\
& A_{i} \text { - agricultural indicator; } \\
& E n_{i} \text { - environmental indicator; } \\
& N_{i} \text { - naturality indicator. }
\end{aligned}
$$


General description of Favorability Index for Development determination in Paris metropolitan area

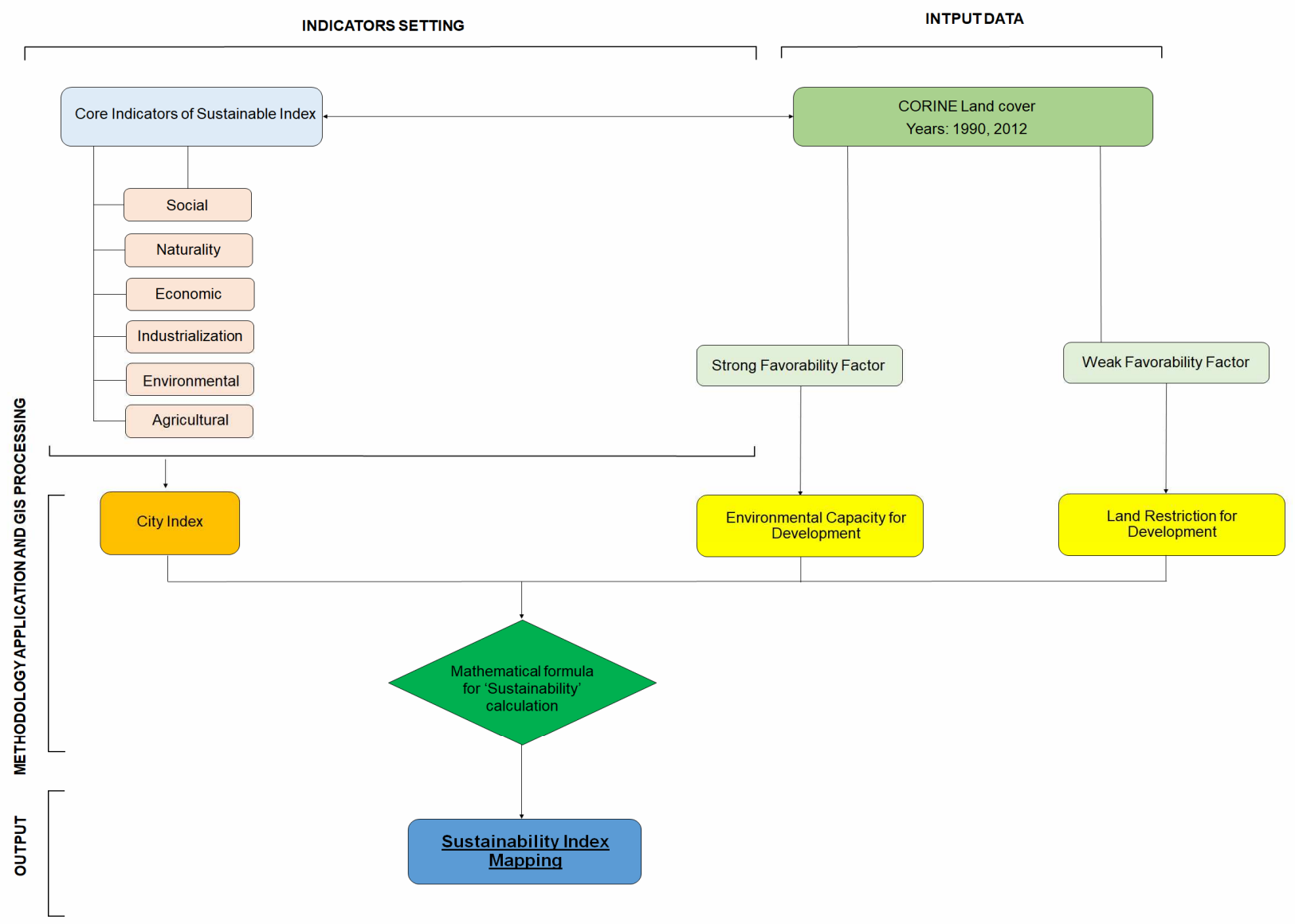

Fig. 3. Schematic diagram showing the methodology steps.

\subsection{Metropolitan Area Sustainability Index (MASI)}

Three layers are used to define the MASI index: City Index, Environmental Capacity for Development, and Land Restriction for Development. The index of sustainability reflects the territory's capacity for development (Eq. (2)).

$$
M A S I=\frac{C I \times E C D}{L R D}
$$

where:

\section{$C I$ - city index;}

$E C D$ - environmental capacity of development;

$L R D$ - land restriction for development.

The spatial setting of indicators and the calculation of City Index were computed in attribute table of the vector data, while the correction factors were calculated using raster data. The MASI index indicates high sustainability in the areas where the City Index and the Environmental Capacity of Development have high values and the Land Restriction for Development has low values. On the other hand, a low sustainability index indicates low City Index and
Environmental Capacity of Development values, but high values of the Land Restriction for Development.

The proposed method is utilized to determine the sustainability of PMA for 1990 and 2012. The 'Raster Calculator' function from ArcGIS was used for the MASI calculation.

\section{RESULTS AND DISCUTION}

\subsection{Variation of land cover in Paris metropolitan area}

The city of Paris expanded on radial directions during 1990-2012, with high concentration in South and South-West (see Figures 2a and b). The observed changes of the land cover between 1990 and 2012 are related to the forest and agricultural areas. The study area is home to many orchards, vineyards, and berry plantations. Water bodies could be found around the entire PMA. The main river crossing the study area is Seine. There are also smaller rivers such as Marne, Oise, Grand Morin, Essonne and Saint Denis Channel. Inland marshes are found in the southern part of the PMA. CORINE Land Cover databases and future model indicate that the urbanization area increased in the recent period and future. 


\subsection{Core indicators and City Index in Paris metropolitan area}

Based on the land cover data for three time periods, the city core indicators and City Index of PMA were calculated at spatial scale. During the 1990s, the social, industrialization, and economic indicators have higher values (o.8-1) mainly in the central and northcentral part of PMA. Few locations from the south and south-east indicate the presence of social and industrialization indicators (0.2-0.4), while the economic indicator was identified only in the central part. The agricultural indicator has extremely high values (0.8-1) in the peripheral areas of the PMA, but the extended territory with significant values is located in the eastern part. The environmental indicator shows low values in almost the entire PMA area, while the naturality indicator appears with significant values in the southern and western parts of PMA. The indicator patterns illustrate close spatial distribution between 1990 and 2012, with a slight reduction at the spatial scale of naturality and industriality.
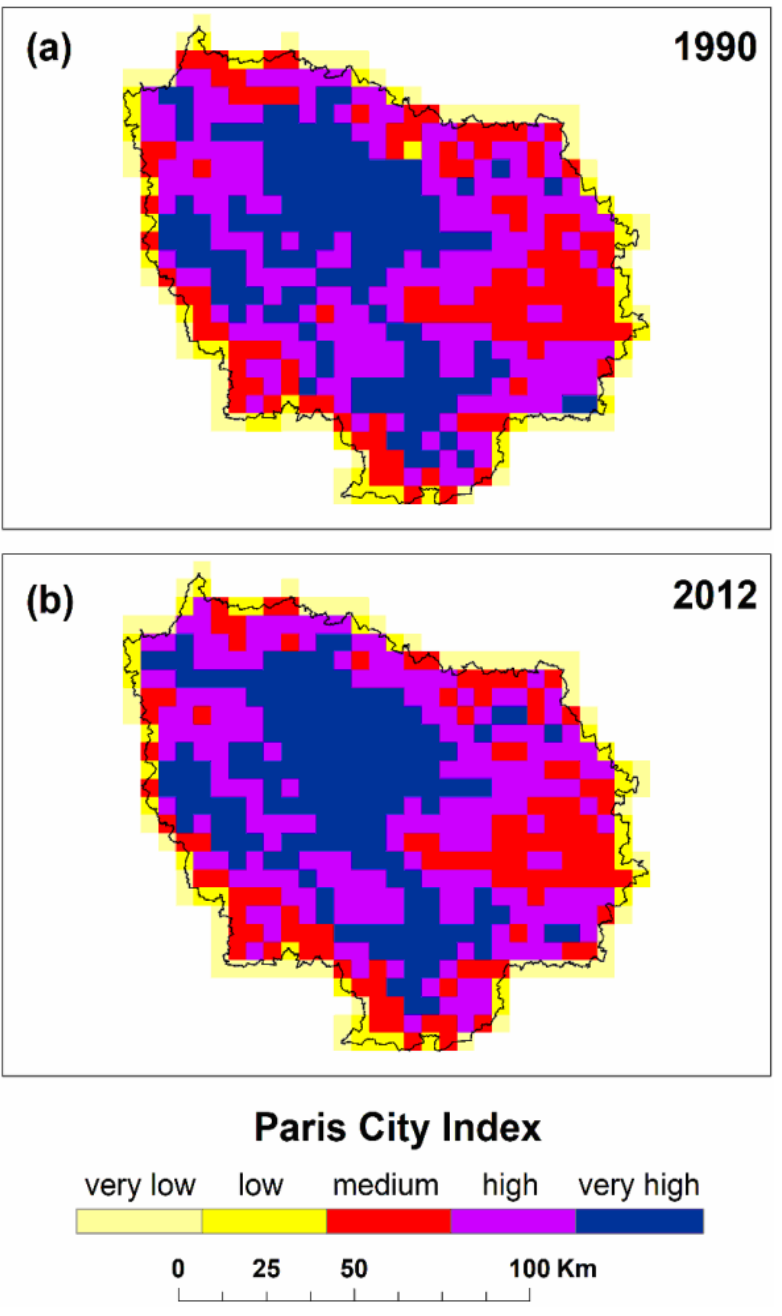

Fig. 4. Spatial distribution of the City Index in the PMA: (a) City index for past (1990s). (b) City index for present (2012).
The City Index map in 1990 shows maximum values ( $>0.8$ ) in the centre, north, west, and south of the PMA. During 2012, the higher values ( $>0.8$ ) extend on larger territory but with appropriate pattern. High values (0.61-0.8) of the City Index characterize large areas of the city in 1990 and 2012 (in the east, south, north, and north-west) (Figures $4 \mathrm{a}$ and $4 \mathrm{~b}$ ). The medium values (0.41-0.6) of the City Index increased between the two years (1990 and. 2012). These values extend mainly in the eastern side, but could be also observed in the peripheral areas. Low and very low values (0-0.2 and 0.21-0.4) were identified along the PMA border, where all indicators recorded low values (due to the cut-off area / artefacts influence).

\subsection{Correction factors in Paris metropolitan area}

In the territory of PMA, the Environmental Capacity of Development has mainly values between 0.61-0.7 and is occupied by non-irrigated lands.
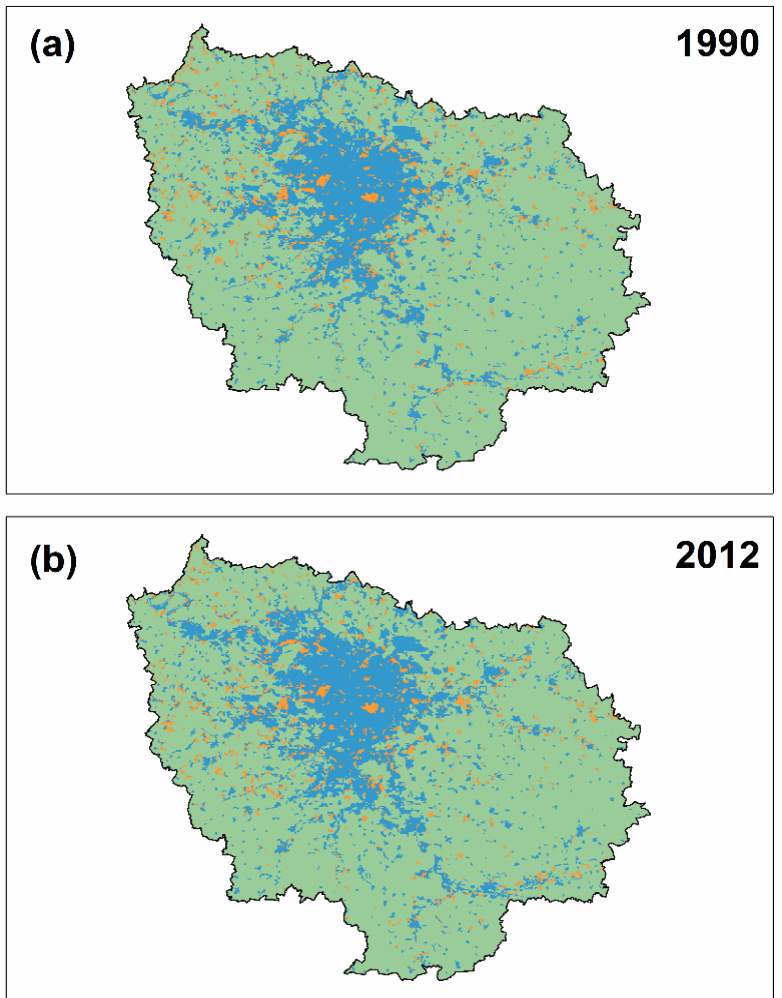

\section{Paris \\ Envinronmental Capacity for Development

$\begin{array}{ccccccc}0.5 & 0.6 & & 0.7 & 0.8 & 0.9 & 1 \\ & \mathbf{0} & \mathbf{2 5} & \mathbf{5 0} & & \mathbf{1 0 0} \mathbf{~ K m} & \end{array}$

Fig. 5. Spatial distribution of the Environmental Capacity for Development in the PMA: (a) Environmental Capacity for Development for past (1990s). (b) Environmental Capacity for Development for present (2012). 
These areas are open-space with no urban development and may supply the city in the future with land for development. Figures $5 \mathrm{a}$ and $5 \mathrm{~b}$ illustrate the 'Environmental Capacity of Development' correction factor for 1990 and 2012. The most favourable lands, where 'Environmental Capacity of Development' reaches values above 0.8 , were sparsely found in the north and south of PMA. Some locations with high values of 'Environmental Capacity of Development' were found in the western part. The low and lowest values extend in the central and north-central parts of the PMA and generally overlap with the urban constructed areas. The variation of 'Land Restriction for Development' at spatial scale has higher values (o.8-1) in the north, south, east, and west parts of the PMA and covers the forest and woodland and shrub lands. Infrastructure and airport areas register maximum values and are located in the north and south of Paris City, but also in some locations from east and south of PMA. Inside urban areas, the values of this factor vary between 0.7 and 0.8 . Lower values were identified in the mineral extraction sites (check again).

Figures $6 \mathrm{a}$ and $\mathrm{b}$ show the spatial distribution of 'Land Restriction for Development' factor over PMA during 1990 and 2012.
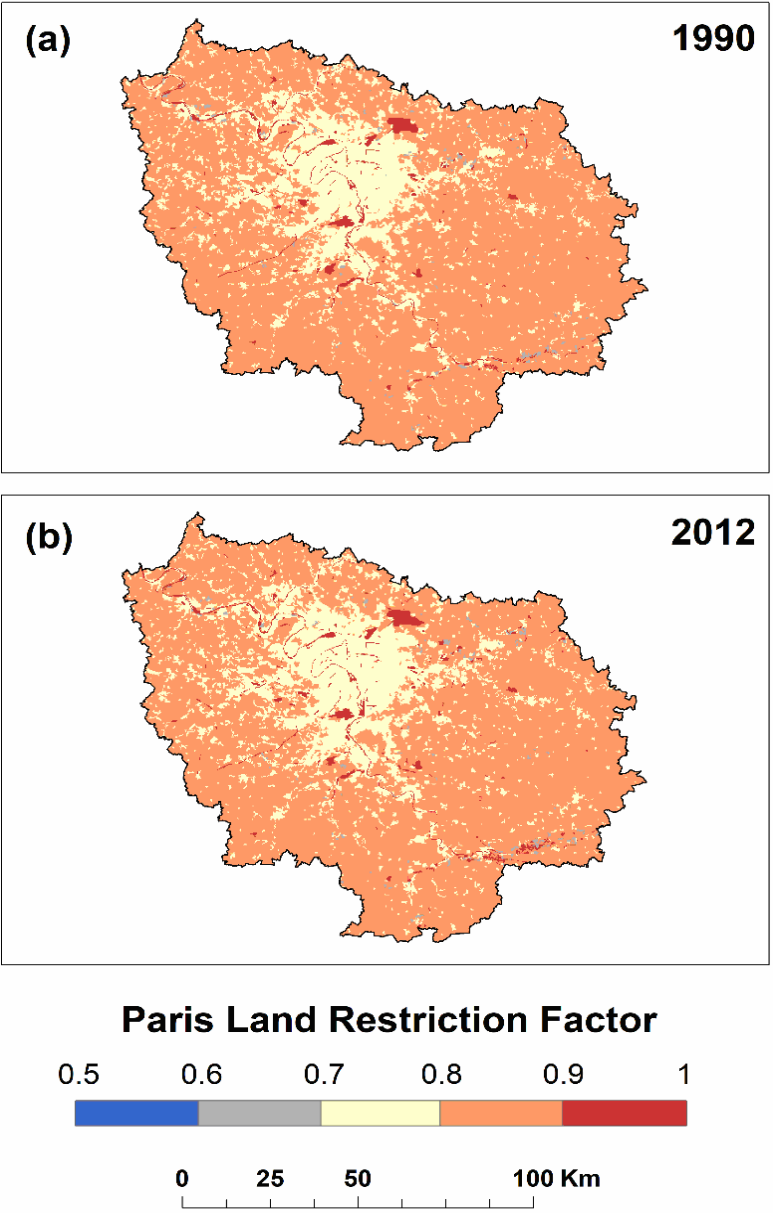

Fig. 6. Spatial distribution of the Land Restriction Factor in the PMA: (a) Land Restriction Factor for past (1990s). (b) Land Restriction Factor for present (2012).

\subsection{Spatial variation of MASI in Paris metropolitan area}

Incorporating the City Index and the two correction factors in the MASI formula, the sustainability maps of PMS in three years were developed (Figure 7). In 1990, the area with very high values of sustainability extended in the north-central part of the PMA and in a few locations east, south, and west of the study area. High sustainability was found mainly in the centre, north, and south of the PMA and sparsely in the east and west. The medium class of sustainability occupies the east, south-west and peripheral areas. The low sustainability extends in the east, south-east, and north-west, mainly near the border. Few locations were identified with very low sustainability values in the north, south, and southwest parts of the PMA (Figure $7 \mathrm{a}$ ).
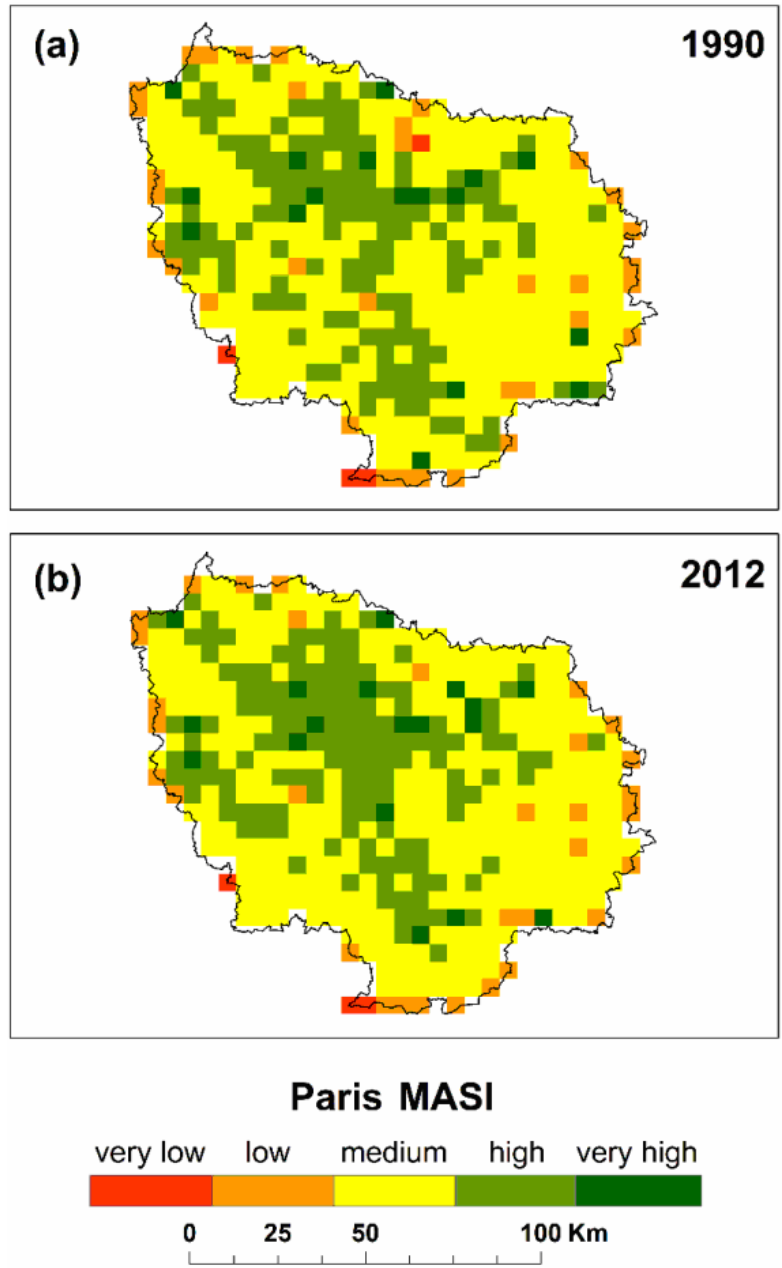

Fig. 7. Spatial distribution of the MASI in the PMA: (a) MASI for past (1990s). (b) MASI for present (2012).

In 2012, the pattern is close to the spatial distribution of sustainability for 1990 (Figure 7b); however, the high and very high sustainability values are even increased in 2012 (by about 2\%). Considerable increases in the high sustainability area were mainly observed in the north-central, southern, and western parts of the PMA, while the medium class reduced in area extension. The low and very low sustainability did 
not change significantly between these two time-frames. The changes show increases of $1.45 \%$ for the high sustainability area between 1990 and 2012, while no significant changes were identified for other classes (Table 2). These results suggest that the PMA land cover can support the human expectations even if the built-up area increases and the urban area is continuously developing.

Table 2. Statistics of the sustainability area for different classes.

\begin{tabular}{l|rr}
$\begin{array}{l}\text { Sustainability } \\
\text { classes }\end{array}$ & $\begin{array}{r}\text { Sustainability } \\
\text { area } \mathbf{1 9 9 0}(\boldsymbol{\%})\end{array}$ & $\begin{array}{r}\text { Sustainability } \\
\text { area 2012 }(\boldsymbol{\%})\end{array}$ \\
\hline Very low & 0.83 & 0.62 \\
Low & 7.02 & 6.61 \\
Medium & 61.16 & 60.12 \\
High & 27.48 & 28.93 \\
Very High & 3.51 & 3.72
\end{tabular}

\subsection{Discussion}

A new sustainability index for the cities and large urban areas was set up in this study. The MASI index was applied for Paris Metropolitan Area based on six indicators that contribute to the City Index calculation and by using two correction factors. The innovative contribution of the study is mainly related to spatiality. Previous research has tackled the great metropolises of the world confronted by massive urbanisation and the ones that struggle for space (Wu et al., 2013). For instance, in the last two decades, many metropolitan areas (e.g. Wuhan, Paris, Hangzhou, Valencia) have increased considerably. Due to this phenomenon onto which we can add poor management, peripheral areas of large cities are faced with mixed urban-rural space, and uncontrolled urban sprawl and immigration flows. This method applied to large cities may contribute towards rapid identification of these locations thus assisting public authorities in making proper decisions. In addition, the sustainability index is a useful tool for environmental management (Singh et al., 2012). Even if some studies refer to the renewable energies and sustainability, they also incorporate the economic and social aspects (Kılkış, 2015).

Our research intends to capitalize on the previous studies on metropolitan area sustainability, proposing a new index, adapted to the complexity and intricacies of metropolitan areas, the Metropolitan Area Sustainability Index (MASI). The index is composed of 6 main indicators (Economic, Industrialization, Social, Agricultural, Environmental, Natural) based on the CORINE Land Cover database. The multi-criteria analysis of these indicators provides a clear perspective on the current land usage as well as a relevant prognosis. The constructive basis of this index derives from the fact that it manages to cover almost the entire spectre of existing entities and their collaboration within a metropolitan area.

Another positive aspect of the paper is the implementation of GIS technology in modelling territorial structures (e.g. metropolitan areas), as GIS provides, through its Spatial Analyst Tools, the ability to combine the information of vector and raster data. Our work is not without limitations. The main data source consists of land cover and the MASI calculation is related to the content and details of these databases (CORINE Land Cover 1990 and 2012). The way in which we combined data is innovative, but still, results are static and carried out mainly with mathematical operations. These findings do not represent a transient model; and for this reason, we were not able to support a sensitivity analysis. However, this topic could be explored in the future. At this stage, the shortcomings do not affect the results at spatial scale. For future implementation and City Index improvement, the energy, water and environment systems data could be incorporated in the analysis (Kılkış, 2016).

Such an analysis, as MASI provides, could be a first step in the implementation of the relational analyses of the metropolitan areas. Moreover, the spatial planning policies of the metropolitan areas and their management are often confidential information and the content of the technical reports are difficult to get or do not include indicators to assess sustainability. Sometimes, this underlines the low capacity of collaboration between the administrative institutions and the research institutions. As Carli et al. (2018) mentioned, sustainable development depends on the benchmarking of metropolitan areas and on providing decision guidelines for the authorities. Our study could be useful for the main universities and governmental authorities for planning practices. Moreover, architects and environmental agencies may take into consideration the MASI index to project the activities and the coming projects in the city. This gap could be now filled with such kind of analysis that we propose in this study and, if necessary, it can be easily modified from one case study to another.

\section{CONCLUSIONS}

The aims of this study were to identify the suitable indicators for the sustainability index in metropolitan areas, to propose a territorial approach for the sustainability assessment in such kind of areas, and to apply this method for Paris Metropolitan Area. CORINE Land Cover databases were used in this study to define the sustainability index at the spatial scale of Paris Metropolitan Area. The indicators served to implement the particular City Index and the integration of this index with the correction factors conducted to the sustainability index calculation. The operations and 
outliers were processed into ArcGIS for the years 1990 and 2012.

Results indicate high and very high values of the Metropolitan Area Sustainability Index in the northcentral, southern, and western parts of the PMA, with an increase of the area with high sustainability for 2012. Low and very low MASI values were identified mainly in the peripheral areas for all three years.

With the contribution of the original maps of PMA, this work can be of high interest for the scientific board of related fields (e.g. territorial management, GIS, economy), but also for policy-makers and urban planning experts. The methodology applied in this study could be replicated in other case studies.

\section{ACKNOWLEDGEMENTS}

Authors would like to thank to the Copernicus Land Monitoring Services for the CORINE land cover raster data.

\section{REFERENCES}

Angel S., Blei A. M., Parent J., Lamson-Hall P., Sánchez N. G. (2016), Atlas of Urban Expansion, vol. 1, Areas and Densities. New York: New York University Urban Expansion Program; United Nations Programme for Human Settlements; Lincoln Institute of Land Policy.

Batty M. (2011), When all the world's a city. Environment and Planning A 43 (4): 765-772.

Bircol G. A. C., de Souzaa M. P., Fontes A. T., Chiarello A. G., Ranieri V. E. L. (2018), Planning by the rules: A fair chance for the environment in a land-use conflict area. Land Use Policy 76: 103-112.

Bolis I., Morioka S. N., Sznelwar L. I. (2014), When sustainable development risks losing its meaning. Delimiting the concept with a comprehensive literature review and a conceptual model. Journal of Cleaner Production 83: 7-20.

Carli R., Dotoli M., Pellegrino R. (2018), Multicriteria decision-making for sustainable metropolitan cities assessment. Journal of Environmental Management 226: 46-61.

Chaloupková M., Kunc J., Dvořák Z. (2018), The creativity index growth rate in the Czech Republic: a spatial approach. Geographia Technica 13(1): 30-40.

Copernicus Land Monitoring Services (2012), CORINE Land Cover of Europe. URL: http://land.copernicus.eu/. Accessed on 21 July 2016.

Correa Ayram C. A., Mendoza M. E., Etter A., Pérez Salicrup D. R. (2017), Anthropogenic impact on habitat connectivity: A multidimensional human footprint index evaluated in a highly biodiverse landscape of Mexico. Ecological Indicators 72: 895-909. Cox W. (2018), The evolving urban form: Paris. Available at http://www.newgeography.com/content/ o05912-the-evolving-urban-form-paris), Accessed on 12.09.2018.

Csurgó B., Kovách I., Mathieu N. (2016), Exploring Innovation and Sustainability in the Metropolitan Rural Areas of Budapest and Paris. Research in Rural Sociology and Development 23: 275-301.

Di Lucia L., Usai D., Woods J. (2018), Designing landscapes for sustainable outcomes - The case of advanced biofuels. Land Use Policy 73: 434-446.

Gardi C., Bosco C., Rusco E., Montanarella L. (2010), An analysis of the Land Use Sustainability Index (LUSI) at territorial scale based on Corine Land Cover. Management of Environmental Quality: An International Journal 21 (5): 680 - 694.

Gonzalez-Mejía A. M., Eason T. N., Cabezas H., Suidan M. T. (2012), Assessing Sustainability in Real Urban Systems: The Greater Cincinnati Metropolitan Area in Ohio, Kentucky, and Indiana. Environmental Science \& Technology 46 (17): 9620-9629.

Holden E., Linnerud K., Banister D. (2014), Sustainable development: Our Common Future revisited. Global Environmental Change 26: 130-139.

Huang L., Wu J., Yan L. (2015), Defining and measuring urban sustainability: a review of indicators. Landscape Ecology 30 (7): 1175-1193.

Johnson B. J., Swearingen White S. (2010), Promoting Sustainability through Transportation Infrastructure? Innovation and Inertia in the Kansas City Metropolitan Area. Journal of Urban Planning and Development 136 (4): 303-313.

Kanyinda A. (2017), Un-Habitat Global Activities Report 2017. [Latha Rengachari (ed.)]. Strengthening partnerships in support of the New Urban Agenda and the Sustainable Development Goals, ISBN (Series): 978-92-1-133406-7, ISBN (Volume): 978-92-1-1327328. Retrieved from: https://unhabitat.org/wpcontent/uploads/2017/o2/GAR2017-FINAL_web.pdf.

Kılkış Ş. (2015) Composite index for benchmarking local energy systems of Mediterranean port cities. Energy 92: 622-638.

Kılkış Ş. (2016), Sustainable development of energy, water and environment systems index for Southeast European cities. Journal of Cleaner Production 130: 222-234.

Lee Y.-J., Huang C.-M. (2007), Sustainability index for Taipei. Environmental Impact Assessment Review 27 (6): 505-521.

Lotze-Campen H., Müller C., Bondeau A., Rost S., Popp A., Lucht W. (2008), Global food demand, productivity growth, and the scarcity of land and water resources: a spatially explicit mathematical programming approach. Agricultural Economics doi:10.1111/j.1574-0862.2008.00336.x.

Lu X., Ke S. (2018), Evaluating the effectiveness of sustainable urban land use in China from the perspective of sustainable urbanization. Habitat International 77: 90-98. 
Masson V., Lion Y., Peter A., Pigeon G., Buyck J., Brun E. (2012), "Grand Paris": regional landscape change to adapt city to climate warming. Climatic Change 117 (4): 769-782.

Milczarek-Andrzejewska D., Zawalińska K., Czarnecki A. (2018), Land-use conflicts and the Common Agricultural Policy: Evidence from Poland. Land Use Policy 73: 423-433.

Mokoena B. T., Musakwa W. (2018), Mobile GIS occupancy audit of Ulana informal settlement in Ekurhuleni municipality, South Africa. Geo-spatial Information Science 1-12, https://doi.org/10.1080/ 10095020.2018.1519349.

Mori K., Yamashita T. (2015), Methodological framework of sustainability assessment in City Sustainability Index (CSI): A concept of constraint and maximisation indicators. Habitat International 45: 10-14.

Mori K., Christodoulou A. (2012), Review of sustainability indices and indicators: Towards a new City Sustainability Index (CSI). Environmental Impact Assessment Review 32: 94-106.

Mori K., Fujii T., Yamashita T., Mimura Y., Uchiyama Y., Hayashi K. (2015), Visualization of a City Sustainability Index (CSI): Towards Transdisciplinary Approaches Involving Multiple Stakeholders. Sustainability 7 (9): 12402-12424.

Nicula A. -S., Stoica M. S., Ilovan O.-R. (2017), The Cultural-Historical and Political Spheres of Influence of Alba Iulia. Transylvanian Review 26 (2): 299-315.

Nistor M. M. (2018), Climate change effect on groundwater resources in South East Europe during the $21^{\text {st }}$ century. Quaternary International 1-10, https://doi.org/10.1016/j.quaint.2018.05.019

Păcurar B.-N., Nicula S.-A., Strinu O., Surd V. (2016), Indexing the Innovative Capability of Romanian NUTS 3 Subdivisions (Counties). Journal of Settlements and Spatial Planning 7 (1): 45-49.
Rojas C., Pino J., Basnou C., Vivanco M. (2013), Assessing land-use and -cover changes in relation to geographic factors and urban planning in the metropolitan area of Concepción (Chile). Implications for biodiversity conservation. Applied Geography 39: 93-103.

Sands G. R., Podmore T. H. (2000), A generalized environmental sustainability index for agricultural systems. Agriculture, Ecosystems \& Environment 79 (1): $29-41$.

Schulp C. J. E., Tieskens K. F., Sturck J., Fuchs R., van der Zanden E. H., Schrammeijer E., Verburg P. H. (2015), EU scale analysis of future cultural landscape dynamics. Report no. 1, WP 5 Fineand broad-scale modelling of future landscapes.

Siche J. R., Agostinho F., Ortega E., Romeiro A. (2008), Sustainability of nations by indices: Comparative study between environmental sustainability index, ecological footprint and the emergy performance indices. Ecological Economics 66 (4): 628-637.

Singh R. C., Murty H. R., Gupta S. K., Dikshit A. K. (2018), An overview of sustainability assessment methodologies. Ecological Indicators 15: 281-299.

Sutton P. C. (2003), An Empirical Environmental Sustainability Index Derived Solely from Nighttime Satellite Imagery and Ecosystem Service Valuation. Population and Environment 24 (4): 293-311.

Turón C., Gomis J. (2016), Implementation of elements of sustainability applied to the urbanization of productive areas. Geographia Technica 11 (2): 113-124.

Wu K., Ye X., Qi Z., Zhang H. (2013), Impacts of land use/land cover change and socioeconomic development on regional ecosystem services: The case of fast-growing Hangzhou metropolitan area, China. Cities 31: 276-284. 